Article

\title{
Knowledge, Attitudes and Referral Patterns of Lynch Syndrome: A Survey of Clinicians in Australia
}

\author{
Yen Y. Tan ${ }^{1,2,3, *}$, Amanda B. Spurdle ${ }^{3}$ and Andreas Obermair ${ }^{1,2}$
}

1 School of Medicine, The University of Queensland, 288 Herston Road, Herston, QLD 4006, Australia; E-Mail: obermair@powerup.com.au

2 Molecular Cancer Epidemiology Laboratory, Genetics and Computational Biology Division, QIMR Berghofer Medical Research Institute, 300 Herston Road, Herston, QLD 4006, Australia

3 Queensland Centre for Gynaecological Cancer Research, Level 6 Ned Hanlon Building, Royal Brisbane and Women's Hospital, Butterfield Street, Herston, QLD 4029, Australia; E-Mail: amanda.spurdle@qimrberghofer.edu.au

* Author to whom correspondence should be addressed; E-Mail: y.tan@uq.edu.au; Tel.: +61-07-3346-5192.

Received: 27 November 2013; in revised form: 24 April 2014 / Accepted: 25 April 2014 /

Published: 12 May 2014

\begin{abstract}
This study assessed Australian clinicians' knowledge, attitudes and referral patterns of patients with suspected Lynch syndrome for genetic services. A total of 144 oncologists, surgeons, gynaecologists, general practitioners and gastroenterologists from the Australian Medical Association and Clinical Oncology Society responded to a web-based survey. Most respondents demonstrated suboptimal knowledge of Lynch syndrome. Male general practitioners who have been practicing for $\geq 10$ years were less likely to offer genetic referral than specialists, and many clinicians did not recognize that immunohistochemistry testing is not a germline test. Half of all general practitioners did not actually refer patients in the past 12 months, and $30 \%$ of them did not feel that their role is to identify patients for genetic referral. The majority of clinicians considered everyone to be responsible for making the initial referral to genetic services, but a small preference was given to oncologists (15\%) and general practitioners (13\%). Patient information brochures, continuing genetic education programs and referral guidelines were favoured as support for practice. Targeted education interventions should be considered to improve referral. An online
\end{abstract}


family history assessment tool with built-in decision support would be helpful in triaging high-risk individuals for pathology analysis and/or genetic assessment in general practice.

Keywords: Lynch syndrome; referral; risk assessment; genetic services; knowledge; attitudes and practice

\section{Introduction}

Lynch syndrome, also known as hereditary nonpolyposis colorectal cancer (HNPCC), is an inherited cancer syndrome caused by defect in one of the mismatch repair (MMR) genes-MLH1, MSH2, MSH6 and PMS2. It accounts for about 5\% of all colorectal and endometrial cancers diagnosed [1,2]. MMR mutation carriers have high risks of early onset colorectal $(25 \%-70 \%)$ or endometrial cancers $(30 \%-70 \%)$, and have increased risks of other cancers such as ovarian, gastric, small bowel, pancreatic, urothelial, brain and skin neoplasms [3,4]. Further, women carrying MMR gene mutations who are diagnosed with endometrial cancer have increased risks of second primary colon cancer (about 40-fold) or other extracolonic cancers (up to 28-fold) compared with that for the general population [5]. Nevertheless, at-risk individuals are dependent on their clinicians for diagnosis and surveillance. Though clinicians cannot be expected to have detailed knowledge about the causative genes of Lynch syndrome, it remains their responsibility to recognize the clinical phenotype and family history characteristics of Lynch syndrome, and make a referral to a clinical genetics service or a familial cancer centre if deemed necessary. However, local and international studies have reported that only a small proportion of individuals suspected to have Lynch syndrome were identified and referred to a clinical genetics service/family cancer clinic for further genetic consultation and possible genetic testing [6-10].

Numerous barriers to referral for genetic services (i.e., genetic consultation and/or testing) have been reported in the literature, including lack of knowledge regarding Lynch syndrome and who should be referred, lack of family history information or referral guidelines, or lack of awareness of clinical genetic services [11,12]. Despite the number of studies on Lynch syndrome, only few included Lynch-associated extracolonic malignancies $[13,14]$. This contributes to the concern that, although there is increasing awareness of Lynch syndrome and colorectal cancer, endometrial and other extracolonic cancers are under-recognized by practicing clinicians. Domanska and colleagues investigated knowledge about key features of Lynch syndrome in 102 clinicians in Southern Sweden reported that not only a majority of clinicians underestimated the risk of endometrial cancer (77\%) but also that of colorectal cancer (56\%) [14]. In a more recent survey about the knowledge of regarding the genetics and recommended screening for carriers of Lynch syndrome mutations, 201 medical students at an American medical school demonstrated lack of awareness of recommendations for endometrial cancer screening for high risk individuals [15]. As it was unclear whether clinicians in Australia face similar challenges as their peers abroad, a qualitative study was conducted to assess barriers and motivators of genetics referral among 28 clinicians who are likely to diagnose, treat and assess Lynch families in Queensland, the second-largest and third-most populous state in Australia [16]. While the authors reported that a majority of clinicians were positive about referring patients to a clinical genetics service, they also found a lack of knowledge and support needed to make an appropriate referral. 
In order to facilitate diagnosis of Lynch syndrome, various guidelines such as the Amsterdam II, revised Bethesda or the Society of Gynecologic Oncologists have been developed [17-19]. Current Australian practice guidelines recommend that young individuals with colorectal cancer, and with a moderate-to-high risk family history of cancer are referred to a clinical genetics service/family cancer clinic, and offered genetic risk assessment and counselling with or without genetic testing i.e., DNA molecular analysis [20]. While the referral of patients to a clinical genetics service/family cancer clinic can be from a general practitioner (GP) or a specialist [21], only specialists apart from geneticist/genetic counsellor can initiate or order tumour molecular analysis i.e., immunohistochemistry (IHC) or microsatellite instability (MSI) testing directly from a pathology service. Routine IHC for MLH1, MSH2, MSH6 and PMS2 proteins has been recommended and supported by the Australian College of Pathologist for all patients diagnosed with colorectal cancer younger than 50 years of age [22], although the actual patterns of care around uptake of this recommendation in Australia is unknown. Further, to our knowledge, such testing has yet to be formally established in Australia and there are currently no standard criteria for referral of individuals with endometrial cancer who are at risk of Lynch syndrome to a clinical genetics service. Genetic testing, on the other hand, is done through clinical genetics services or family cancer clinics, and is free if a patient presents with a high clinical suspicion of an underlying genetic aetiology.

As early identification of mutation carriers allows for more intensive colonoscopic surveillance and consideration of risk-reducing surgeries [23-27], it is important that patients diagnosed with colorectal cancer or endometrial cancer are identified and appropriately triaged for clinical evaluation. We therefore distributed a questionnaire to: (1) investigate clinicians' knowledge of Lynch-associated cancer risks and tumour molecular analysis; (2) assess referral practices among clinicians who are likely to diagnose, treat and survey Lynch families; (3) quantify motivators and barriers to genetics referral for Lynch syndrome in Australia; and (4) explore physician referral preferences (i.e., preferred timing for referral and who they think might be the most appropriate professional to make the initial genetics referral), perceptions of their role and their desired support for the provision of genetic services.

\section{Experimental}

\subsection{Participants and Procedures}

We targeted our sample to clinicians who are likely to diagnose, treat and survey Lynch families. Participants therefore included GPs and specialist groups (i.e., gynaecologists, gastroenterologists, medical oncologists, radiation oncologists, gynaecology oncologists, general and colorectal surgeons), who were identified through membership list of the Australian Medical Association. We purchased the list from AMPCo Data direct, a subsidiary of the Association who owns the list of practicing doctors $(\mathrm{N}=11,624)$, who then broadcasted our invitation to their members. An invitation was circulated by email to a randomly stratified sample of 1674 participants. Sample size was calculated to provide $90 \%$ power, with a two-sided significant level of $\alpha=0.06$. The email described the study and confidentiality, and included a link to the online survey and participant information sheet. Participants were asked to read the information brochure prior to commencing the survey. A reminder email was sent a week apart from the initial broadcast. Responders were allowed to save their responses and 
return to complete the survey at a later time. Due to the small sample size of oncologists from the Australian Medical Association database, oncologists were also identified from the membership of Clinical Oncological Society of Australia membership directory. An invitation email was sent to gynaecological oncologists, medical oncologists and radiation oncologists by the Society, and was followed-up with a reminder email sent a week after the initial broadcast. Only one reminder email was sent to all invited study participants. Participation was voluntary and no financial incentives were given. Survey response implied consent to participate, and all responses were anonymous. The study was approved by The University of Queensland School of Medicine and Royal Brisbane \& Women's Hospital research ethics committees.

\subsection{Instrumentation}

A web-based survey was developed specifically for this study based on a review of relevant literature [13,28-32], results from our previous qualitative study [16], and using the advice of a panel of experts with expertise in gynaecology oncology, clinical genetics, psycho-oncology, and genetic counselling. The survey items were pilot-tested with a convenience sample of 10 health professionals (i.e., oncologists, geneticists, clinical and social researchers) to assess relevance and face validity of survey items. Changes to the survey were made accordingly using the Delphi method [33] before administration.

The final version of the survey was created using LimeSurvey and consisted of 19 items (see Appendix 1). Items included participant demographics, referral practices, barriers and motivators for genetics referral, physician referral preferences and perceptions of their role and their desired support for the provision of genetic services. In order to evaluate clinicians' knowledge of Lynch syndrome, the authors adapted a pedigree from a previous study that addressed risk assessment abilities and referral patterns to fit the high-risk profile for Lynch syndrome [28]. At the end of the survey, participants were asked to provide additional comments and their email address if they wish to receive a copy of the research summary report. The survey was open for three months from mid-March to end of May 2013.

\subsection{Data Analyses}

All survey data were collected using LimeSurvey, and data were coded and analysed using SPSS Version $20\left(\right.$ IBM $^{\circledR}$ SPSS $^{\circledR}$ Statistics, Chicago, IL, USA). Descriptive statistics included frequencies and proportions were calculated. $x^{2}$ or Fisher's exact test was used to investigate associations between categorical variables. Throughout the analysis, respondents who selected unsure were designated as missing data. All p-values were two-sided, with a statistical significance level set at $p<0.05$.

\section{Results}

Of 582 email recipients who "opened" the email, $144(24.7 \%)$ responded to the web survey fully $(138 / 144,95.8 \%)$ or partially (more than $50 \%$ of questions answered, 6/144, 4.2\%). Demographics of these clinicians are summarized in Table 1. Overall, the study sample consisted of 59 oncologists (40\%), 27 surgeons (19\%), 24 gynaecologists (17\%), 18 GPs (13\%) and 11 gastroenterologists (8\%); the remaining 5 were designated as other specialties (4\%). Most clinicians were $<50$ years of age 
$(p=0.005)$, and were in practice for at least 10 years $(p=0.002)$. There were no statistically significant differences between gender or state of residence with provider groups.

Table 1. Sociodemographics of participating health care provider groups ${ }^{\mathrm{a}}$.

\begin{tabular}{|c|c|c|c|c|c|c|c|}
\hline & Total & GP & GYN & GE & ONC & SURG & Others $^{b}$ \\
\hline & $N(\%)^{c}$ & $N(\%)^{c}$ & $N(\%)^{c}$ & $N(\%)^{c}$ & $N(\%)^{c}$ & $N(\%)^{c}$ & $\mathbf{N}(\%)^{\mathrm{c}}$ \\
\hline Total & $144(100)$ & $18(100)$ & $24(100)$ & $11(100)$ & $59(100)$ & $27(100)$ & $5(100)$ \\
\hline \multicolumn{8}{|l|}{ Age (years) } \\
\hline$<50$ & $84(58)$ & $10(56)$ & $11(46)$ & $6(55)$ & $37(63)$ & $17(63)$ & $3(60)$ \\
\hline$\geqslant 50$ & $60(42)$ & $8(44)$ & $13(54)$ & $5(46)$ & $22(37)$ & $10(37)$ & $2(40)$ \\
\hline \multicolumn{8}{|l|}{ Gender } \\
\hline Female & $67(47)$ & $8(44)$ & $8(33)$ & $\mathbf{0}$ & $37(63)$ & $9(33)$ & $5(100)$ \\
\hline Male & $77(53)$ & $10(56)$ & $16(67)$ & $11(100)$ & $22(37)$ & $18(67)$ & $\mathbf{0}$ \\
\hline \multicolumn{8}{|c|}{ Years of Practice in Specialty } \\
\hline$<10$ & $59(41)$ & $5(28)$ & $7(29)$ & $4(36)$ & $27(46)$ & $12(44)$ & $4(80)$ \\
\hline$\geqslant 10$ & $85(59)$ & $13(72)$ & $17(71)$ & $7(64)$ & $32(54)$ & $15(56)$ & $1(20)$ \\
\hline \multicolumn{8}{|l|}{ State $^{d}$} \\
\hline NSW/ACT & $44(31)$ & $6(33)$ & $9(38)$ & $\mathbf{0}$ & $18(31)$ & $9(33)$ & $3(60)$ \\
\hline VIC/TAS & $44(31)$ & $2(11)$ & $5(21)$ & $4(36)$ & $20(34)$ & $11(41)$ & $2(40)$ \\
\hline QLD & $29(20)$ & $5(28)$ & $11(46)$ & $2(18)$ & $9(15)$ & $3(11)$ & 0 \\
\hline SA & $11(8)$ & $2(11)$ & 0 & $3(27)$ & $6(10)$ & 0 & 0 \\
\hline WA & $16(11)$ & $3(17)$ & $1(4)$ & $2(18)$ & $6(10)$ & $4(15)$ & 0 \\
\hline
\end{tabular}

Abbreviations: GPs general practitioners; GYNs gynaecologists; GEs gastroenterologists; ONCs oncologists; SURGs surgeons; NSW New South Wales; ACT Australian Capital Territory; VIC Victoria; TAS Tasmania; QLD Queensland; SA South Australia; WA Western Australia ${ }^{a}$ Bolded estimates indicate statistically significant difference between two groups within each practice category; ${ }^{\mathrm{b}}$ Other medical specialties include cancer care coordinator $(n=1)$, genetic counsellor $(n=1)$, psycho-oncologists $(n=2)$, social worker $(n=1) ;{ }^{\mathrm{c}}$ The $\%$ reflects the percentage responding within each practice category; ${ }^{\mathrm{d}}$ ACT and TAS were consolidated with NSW and VIC, respectively, due to low participation rate and similarity in genetic testing protocols.

\subsection{Referral to Genetics Services and Ordering Diagnostic Testing for Lynch Syndrome}

Table 2 displays clinician likelihood to refer patients to genetic services and ordering diagnostic testing for Lynch syndrome in the past 12 months, by the provider group. Overall, there were no significant differences between specialist groups and likelihood to refer to genetic services. However, GPs, particularly male practitioners who have been in practice for more than 10 years, were less likely to refer patients to genetic services than others $\left(x^{2}=16 ; p=0.001 ; 25 \% v s .87 \%\right)$. GPs and gynaecologists were significantly less likely to order IHC testing ( $p=0.002$ and $p=0.003$, respectively), whereas oncologists and surgeons were more likely to order such testing ( $p=0.03$ and $p=0.004$, respectively). GPs and gynaecologists were also less likely to order MSI testing ( $p=0.003$ and $p=0.004$, respectively), but surgeons were more likely than the others to order MSI testing $(p=0.005)$. Oncologists were more likely than other provider groups to order DNA germline testing $(p=0.007)$, whereas gynaecologists were less likely to do so. There were no statistically significant differences between age, gender, state of residence or years in practice and referral to genetic services. 
Table 2. Likelihood that clinicians reported referring patients to clinical genetic services or ordering tumour analysis in the past 12 months, by provider group $^{\mathrm{a}, \mathrm{b}}$.

\begin{tabular}{|c|c|c|c|c|c|c|c|}
\hline & $\begin{array}{c}\text { Total } \\
(\mathrm{N}=144)\end{array}$ & $\begin{array}{c}\text { GP } \\
(\mathbf{N}=\mathbf{1 8})\end{array}$ & $\begin{array}{c}\text { GYN } \\
(\mathbf{N}=\mathbf{2 4})\end{array}$ & $\begin{array}{c}\text { GE } \\
(\mathbf{N}=\mathbf{1 1})\end{array}$ & $\begin{array}{c}\text { ONC } \\
(\mathbf{N}=\mathbf{5 9})\end{array}$ & $\begin{array}{c}\text { SURG } \\
(\mathbf{N}=\mathbf{2 7})\end{array}$ & $\begin{array}{c}\text { Others }^{c} \\
(\mathrm{~N}=5)\end{array}$ \\
\hline & $N(\% ; 95 \% C I)^{d}$ & $\begin{array}{c}\mathrm{N}(\% ; 95 \% \mathrm{CI})^{\mathrm{d}} \\
p \text {-value }\end{array}$ & $\begin{array}{c}\mathrm{N}(\% ; 95 \% \mathrm{CI})^{\mathrm{d}} \\
p \text {-value }\end{array}$ & $\begin{array}{c}\mathrm{N}(\% ; 95 \% \mathrm{CI})^{\mathrm{d}} \\
p \text {-value } \\
\end{array}$ & $\begin{array}{c}\mathrm{N}(\% ; 95 \% \mathrm{CI})^{\mathrm{d}} \\
p \text {-value }\end{array}$ & $\begin{array}{c}\mathrm{N}(\% ; 95 \% \mathrm{CI})^{\mathrm{d}} \\
p \text {-value } \\
\end{array}$ & $\begin{array}{c}\mathrm{N}(\% ; 95 \% \mathrm{CI})^{\mathrm{d}} \\
p \text {-value } \\
\end{array}$ \\
\hline Referred patients & & $9(50 ; 29-71)$ & $19(79 ; 60-91)$ & $10(91 ; 62-98)$ & $50(85 ; 73-92)$ & $22(81 ; 63-92)$ & $2(50)$ \\
\hline to genetic services & $112(78 ; 70-84)$ & 0.003 & 0.969 & 0.458 & 0.095 & 0.799 & 0.196 \\
\hline Ordered tumour & & $4(22 ; 9-45)$ & $6(25 ; 12-45)$ & $8(73 ; 43-90)$ & $39(66 ; 53-77)$ & $20(74 ; 55-87)$ & 0 \\
\hline IHC testing & $77(53 ; 45-61)$ & 0.002 & 0.003 & 0.524 & $\mathbf{0 . 0 3 0}$ & 0.004 & - \\
\hline Ordered tumour & & $1(6 ; 1-26)$ & $3(13 ; 4-31)$ & $6(55 ; 28-79)$ & $29(49 ; 37-62)$ & $16(59 ; 41-75)$ & 0 \\
\hline MSI testing & $55(38 ; 31-46)$ & 0.002 & 0.004 & 0.527 & 0.075 & 0.005 & - \\
\hline Ordered DNA & $67(47 \cdot 39-55)$ & $6(33 ; 16-56)$ & $7(29 ; 15-49)$ & $3(27 ; 10-57)$ & $36(61 ; 48-72)$ & $15(56 ; 37-72)$ & 0 \\
\hline mutation testing & & 0.125 & $\mathbf{0 . 0 3 4}$ & 0.308 & $\mathbf{0 . 0 0 7}$ & 0.249 & - \\
\hline
\end{tabular}

Abbreviations: GP general practitioners; GYN gynaecologists; GE gastroenterologists; ONC oncologists; SURG surgeons; CI confidence interval; IHC immunohistochemistry; MSI microsatellite instability. ${ }^{\mathrm{a}}$ Category totals may be less than the total number of respondents due to missing values; ${ }^{\mathrm{b}}$ Bolded estimates indicate significant findings; ${ }^{\mathrm{c}}$ Other medical specialties include cancer care coordinator $(n=1)$, genetic counsellor $(n=1)$, psycho-oncologists $(n=2)$, social worker $(n=1)$; ${ }^{\mathrm{d}}$ The $\%$ reflects the percentage responding within each practice category. 


\subsection{Risk and Surveillance Strategies among Clinicians}

When participants were presented with a fictitious high-risk Lynch-specific clinical scenario (Appendix 1), only 13/144 (9\%) of all respondents were able to answer all Lynch cancer risk-associated questions correctly, i.e., no elevated risk for breast or thyroid cancer, somewhat higher risk for ovarian and gastric cancer, and much higher risk for colorectal and endometrial cancer as compared to the general population. Of all respondents, $65 \%$ could correctly identify colorectal cancer risk, followed by $63 \%$ for thyroid cancer, $60 \%$ for endometrial cancer, $45 \%$ for gastric cancer and $42 \%$ for ovarian cancer. About a third of all respondents considered the fictitious high-risk asymptomatic individual to be at lower risk of developing colorectal and endometrial cancer when compared to the general population, but half of all respondents considered the individual to have a much higher risk for developing ovarian cancer, and another $15 \%$ considered the individual to have a much higher risk for developing gastric cancer. A notable 44\% considered the individual to have high risk for breast cancer. There were no statistically significant differences in specialist groups, age, gender, state of residence or years in practice with providing the correct answers. Nevertheless, GPs were less likely than other specialists to recognize high risk for colorectal cancer $\left(x^{2}=9 ; p=0.003 ; 33 \% v s\right.$. 69\%) and endometrial cancer $\left(x^{2}=6 ; p=0.015 ; 33 \%\right.$ vs. 64\%).

When asked if they consider IHC or MSI testing a germline test, $9 \%$ of all respondents thought IHC was a germline test, while another $23 \%$ considered MSI a germline test. Forty-nine percent and 35\% of all respondents did not consider IHC or MSI a germline test, respectively. Forty-two percent of all respondents were uncertain about both tests. GPs (89\%) and gynaecologists (75\%) were less likely to answer the question on IHC correctly ( $p<0.05$ for both groups), while oncologists $(68 \%)$ were more likely to answer the question correctly $(p<0.001)$ and refer patients for genetic services $(p=0.008)$.

When a high risk individual was affected with endometrial cancer, respondents indicated they would: assess family history (96\%); refer to a geneticist (94\%); discuss Lynch syndrome cancers with the patient (82\%); offer cancer surveillance (77\%); order IHC or MSI tumour testing (58\%); discuss risk-reducing surgeries (53\%); order germline testing (42\%); and refer to non-genetics specialists (38\%); and no further action (1\%). For those who offered cancer surveillance and discuss risk-reducing surgeries, they recommended colonoscopy (87\%), gastroscopy (62\%), serum CA125 (48\%), hysterectomy and bilateral salpingo-oophorectomy (41\%), breast ultrasound $(36 \%)$, subtotal or segmental colectomy ( $8 \%)$, pelvic ultrasound (7\%) and mastectomy $(4 \%)$.

\subsection{Prevalence of Motivators and Barriers to Referral}

As shown in Table 3, a number of motivators and barriers for referral to genetic services were examined. Patient disinterest was considered the biggest barrier to referral. Clinicians that have never referred patients for genetic services were more likely to denote the following barriers to referral: unfamiliarity with hereditary cancer syndromes $(p=0.04)$; no knowledge of how to make referral $(p \leq 0.001)$; no access to a genetic health service $(p=0.001)$; no recommendation and guidelines for referral $(p=0.016)$. 
Table 3. Motivators and barriers of referral of patients suspected with Lynch syndrome for genetic services *.

\begin{tabular}{|c|c|c|c|c|c|}
\hline & \multicolumn{2}{|c|}{$\begin{array}{l}\text { Have not Referred for Genetic } \\
\text { Services (Total = 30) N }(\%)^{a}\end{array}$} & \multicolumn{2}{|c|}{$\begin{array}{l}\text { Referred for Genetic Services } \\
\left(\text { Total = 112) N (\%) }{ }^{\text {a }}\right.\end{array}$} & \multirow[t]{2}{*}{ p-value ${ }^{\mathrm{b}}$} \\
\hline \multicolumn{5}{|c|}{ Motivators } & \\
\hline To provide genetic counselling for the patient & 20 & (66) & 103 & (92) & $<0.001$ \\
\hline Patient interest or request & 20 & (66) & 92 & (82) & 0.065 \\
\hline To provided appropriate screening and/or management for the patient's family & 15 & $(50)$ & 94 & (84) & $<0.001$ \\
\hline To provide appropriate cancer risk assessments for the patient & 21 & (70) & 98 & (88) & 0.544 \\
\hline To provide genetic testing for germline mutations & 14 & (47) & 83 & (74) & 0.004 \\
\hline Reassurance for the patient and family & 16 & (53) & 73 & $(65)$ & 0.234 \\
\hline Ethical and legal responsibility & 14 & (47) & 70 & (63) & 0.117 \\
\hline To provide appropriate screening and management for the patient & 20 & (66) & 81 & (72) & 0.544 \\
\hline Others $^{c}$ & 0 & & 5 & (4) & - \\
\hline \multicolumn{6}{|c|}{ Barriers } \\
\hline Patient was not interested when referral was offered & 17 & $(57)$ & 62 & $(55)$ & 0.898 \\
\hline Patient may be at risk for insurance discrimination & 5 & (17) & 19 & (17) & 0.969 \\
\hline Recommendations and guidelines were not available to select patients for referral & 8 & (27) & 11 & (10) & 0.016 \\
\hline Patient is unlikely to benefit from genetic counselling/testing & 1 & (3) & 16 & (14) & 0.123 \\
\hline I do not feel familiar with hereditary cancer syndromes & 5 & (17) & 6 & $(5)$ & 0.040 \\
\hline Long waiting time for appointment at genetics clinic & 2 & (7) & 7 & $(6)$ & 0.934 \\
\hline I do not know how to make a referral to the local genetic health service & 7 & (23) & 1 & (1) & $<0.001$ \\
\hline I do not have access to genetic health service & 6 & (20) & 2 & $(2)$ & 0.001 \\
\hline I do not feel it is my responsibility & 2 & (7) & 1 & $(1)$ & 0.113 \\
\hline Others ${ }^{\mathrm{d}}$ & 0 & & 4 & $(4)$ & - \\
\hline
\end{tabular}

* For referral to genetic services, total respondents were 142 in total. ${ }^{a}$ The $\%$ reflects the percent responding within each category; ${ }^{\mathrm{b}}$ Bolded estimates indicate significant findings between clinicians who have referred $(n=112)$ and did not refer $(n=30)$ patients for genetic services; ${ }^{\mathrm{c}}$ Qualitative answers were provided, which include antenatal diagnosis, significant family history, significant tumour testing results, to provide the necessary routine surveillance and advice regarding screening and risk-reducing options for patients; ${ }^{\mathrm{d}}$ Qualitative answers were provided, which include lack of resources and no prophylactic treatment or screening available for patients. 


\subsection{Referral preferences, Perceived Role and Desired Support for the Delivery of Genetic Services among Clinicians}

There was no statistically significant difference between provider groups and preferred timing for referral. Clinicians indicated referral should be warranted at any time $(51 \%)$ and when family history is collected (27\%). Although a majority of clinicians felt that everyone is responsible for referring patients to genetic services, a proportion of clinicians believe that oncologists (15\%) and GPs (13\%) would be best suited for the role $(p=0.031)$. Oncologists were preferred as they would most likely recognize at-risk individuals, whereas GPs were preferred because they are the first point of contact for patients, who have the best knowledge about patients' family history and are the ones responsible for coordinating care. However, compared to the specialist groups, some GPs did not feel that their role is to identify patients for referral to genetic services $\left(x^{2}=7 ; p=0.011 ; 30 \% v s .10 \%\right)$ or to order IHC or MSI testing $\left(x^{2}=11 ; p=0.001 ; 20 \%\right.$ vs. $\left.2 \%\right)$. Table 4 further shows clinicians' perceived roles and referral for genetic services. Clinicians who have referred for genetic services considered themselves to be responsible for (1) identifying and referring individuals to clinical genetics services; (2) interpreting germline DNA mutation testing results; (3) ordering IHC or MSI tests; (4) discussing cancer surveillance and prophylaxis with patients; and (5) providing regular clinical exams and care to patients with hereditary cancer syndromes. The support desired for delivering genetic services is summarized in Figure 1.

Figure 1. Desired support for the delivery of genetic services among health care providers.

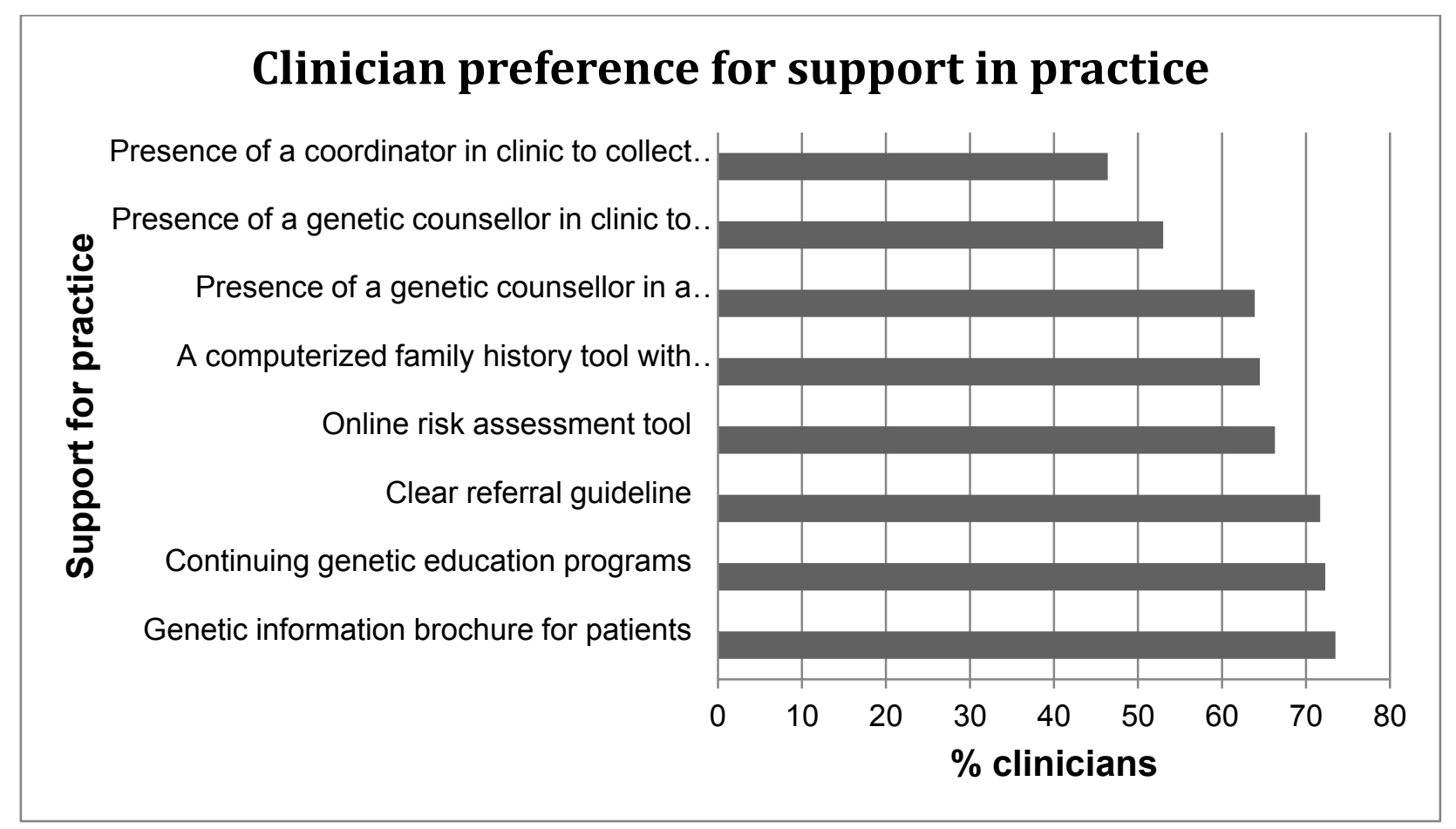


Table 4. Clinicians' perceived roles and referral of patients suspected with Lynch syndrome genetic services *.

\begin{tabular}{|c|c|c|c|}
\hline Perceived Roles & $\begin{array}{l}\text { Have not referred for genetic } \\
\text { services }(\text { Total }=30) \mathbf{N}(\%)^{\text {a }}\end{array}$ & $\begin{array}{l}\text { Referred for genetic services } \\
\quad(\text { Total = 112) N (\%) }\end{array}$ & $p$-value ${ }^{\mathrm{b}}$ \\
\hline Providing emotional support after genetic testing & $21(70)$ & $64(57)$ & 0.202 \\
\hline Identifying patients for referral to genetic services & $19(63)$ & $104(93)$ & $<0.001$ \\
\hline Interpreting germline DNA-based genetic test results & 0 & $22(20)$ & 0.004 \\
\hline Collecting a three-generation family history information & $11(37)$ & $54(48)$ & 0.260 \\
\hline Ordering pre-genetic testing of tumour tissue (e.g., MSI or IHC) & $5(17)$ & $53(47)$ & 0.002 \\
\hline Counselling patients about their cancer risks after genetic testing & $8(27)$ & $38(34)$ & 0.450 \\
\hline Counselling patients about their cancer risks before genetic testing & $7(23)$ & $42(38)$ & 0.147 \\
\hline Calculating relative risk of cancer associated with family cancer history & $4(13)$ & $25(22)$ & 0.321 \\
\hline Discussing the need for cancer surveillance or prophylaxis with patients when required & $17(57)$ & $90(80)$ & 0.011 \\
\hline Providing regular clinical examination and care to patients with hereditary cancer syndromes & $15(50)$ & $82(73)$ & 0.015 \\
\hline Other & $3(10)^{\mathrm{c}}$ & $5(5)$ & - \\
\hline
\end{tabular}

${ }^{*}$ For referral to genetic services, total respondents were 142 in total. ${ }^{a}$ The $\%$ reflects the percentage responding within each category; ${ }^{b}$ Bolded estimates indicate significant findings between clinicians who have referred $(n=112)$ and did not refer $(n=30)$ patients for genetic services; ${ }^{\mathrm{c}}$ Qualitative answers were provided, which include liaison with genetic services, psychotherapy and specialty specific to one particular general surgeon; ${ }^{\mathrm{d}}$ Qualitative answers were provided, which include advice on sequence of treatment modalities, antenatal advice and diagnosis, counselling provided in addition to that provided by genetic service, clear documentation to clinicians, ensuring patient informs family of risk, and referring to appropriate services. 


\section{Discussion}

In 2009, a total of 2105 patients were diagnosed with endometrial cancer in Australia [34]. As the prevalence of Lynch-associated endometrial cancer among mutation-positive women is comparable to that reported internationally [35], it would be expected that about 100 cases diagnosed annually would be due to Lynch syndrome. Establishing a pathogenic mutation carrier in a family is important since it enables predictive testing to be offered to family members, and allow decisions to be made about screening, risk-reducing surgery and chemoprevention if found to be MMR mutation positive [23-26]. While genetic testing is typically offered free of charge and always in the context of genetic counselling at an accredited clinic in Australia [36], access to publically funded genetic services requires a referral from either a GP or a medical specialist [37]. It is therefore essential that clinicians in general recognize the classical family history indicators for Lynch syndrome when individuals present in everyday practice. To our knowledge, this is the first study to formally examine the knowledge, attitudes and referral patterns of Lynch syndrome in Australia. Overall, our findings demonstrated suboptimal knowledge of Lynch syndrome. The presented fictitious individual-a female patient - has a remarkable family history of cancer representing that of revised Amsterdam II criteria. However, a third of clinicians, particularly GPs, did not consider the female patient to have high risk of colorectal or endometrial cancer (which is a concern as MMR mutation carriers have the highest lifetime risk for developing colorectal and/or endometrial cancer amongst the general population). In contrary, about half of all clinicians considered the female patient to have high risks of breast or ovarian cancers (which is another concern as MMR mutation carriers have up to $14 \%$ increased risk of ovarian cancer, and breast cancer has yet to be recognized as part of the Lynch syndrome spectrum of tumours) [4]. This suggests that clinicians could recognize the underlying genetic predisposition in the female patient, but lack familiarity with Lynch syndrome spectrum of tumours. However, this lack of familiarity with Lynch syndrome is consistent with other studies [29,38-40], reflecting the need to establish new ways to reach out to clinicians who are likely to diagnose, treat and survey Lynch families.

Parallel to this finding, we showed that GPs and gynaecologists were less familiar with IHC or MSI testing compared to the specialists. Nevertheless, this is expected, as only specialists apart from geneticist/genetic counsellor can initiate or order IHC or MSI tests directly from a pathology service. However, a proportion of specialists, including surgeons, was not familiar with IHC or MSI testing and was not certain if they were germline tests. The Royal College of Pathologists of Australia considers both IHC and MSI to be tests that assist in characterizing patient's tumour, and do not constitute genetic testing for a familial disorder [41]. IHC and MSI testing are useful not only to identify patients with suspected Lynch syndrome but also to recognize suspected patients who do not meet the Amsterdam criteria for subsequent germline DNA sequencing. Both IHC and MSI provide predictive and prognostic information that may be used to guide treatment decisions. It is therefore important that clinicians know what these tests are so that accurate diagnosis and proper clinical management are warranted for at-risk patients and their family members to reduce cancer risk. Our above results raise concerns, as this implies that the clinicians might not know the purpose of IHC or MSI testing, and may not able to interpret the results correctly even when patients are tested. Thus, adoption of universal, or even age-selected, IHC testing of colorectal and endometrial tumours will reduce issues 
around poor identification of Lynch syndrome cases based on family-history selection criteria. However, there will still be need for targeted genetic education to improve physician understanding of IHC results, and subsequent referral of patients and their relatives for genetic testing and appropriate medical management.

Our results also show that clinicians were not familiar with cancer risk management associated with Lynch syndrome. Although the majority of clinicians recommended colonoscopy for high-risk patients, they also recommended gastroscopy, serum CA125, pelvic ultrasound and mastectomy. According to the eviQ Australian guideline (Appendix 2) and international recommendations [3,42], there is currently no evidence to support a survival benefit from gastroscopy, CA125 or pelvic ultrasound. Current recommendation for breast cancer, which is yet to be considered as part of Lynch syndrome tumour spectrum, is biannual mammography from age 45 or 50 years. Our results suggest that referral, if made, will not always be appropriate, as is unnecessary referral for screening and prophylactic surgeries.

While the majority of clinicians reported that they would assess family history and refer for genetic services when an asymptomatic individual present with a significant family history suggestive of Lynch syndrome, numerous barriers in collecting the information have been reported [43-46]. These include limitations of patients' family history knowledge, time available for collection, knowledge and skills to collect and interpret family history data to provide appropriate risk assessment and clinical care recommendations. Nonetheless, it is important to collect a three-generation pedigree from individuals with a diagnosis of cancer, as this informs eligibility for mutation testing, and readily identifies members in the extended family who are eligible for predictive testing if a pathogenic mutation is identified in the proband. Published data have shown that time devoted on family history collection was often minimal in general practice [43], and inadequate even when documented for cancer patients [8,47-49].

Clinicians in our study considered patient disinterest to be a barrier to uptake of referral. Several published reports have demonstrated low rate of uptake of genetic counselling and testing by at-risk relatives (23\% and 44\%, respectively) [50,51]. An investigation by Wakefield et al. [52] involving 39 high-risk Australian patients for breast and/or ovarian cancer revealed positive attitude toward genetic counselling and testing but patient barriers to clinical attendance and testing uptake were poor understanding of cancer risk and eligibility for genetic testing [52]. It is possible that individuals at risk of Lynch syndrome may face similar challenges; however, no study to date has explicitly assessed Lynch cancer patients' information needs. Our findings also suggest a slight preference by all respondents for the oncologists and GPs to make the initial referral for genetic services; however, a significant proportion of GPs did not feel that their role is to identify patients for genetics referral or to order IHC or MSI testing. As such, it is important to consider alternative methods to triage patients with suspected Lynch syndrome. Universal testing should be considered in Australia; however, to our knowledge such testing has yet to be formally established. Also, due to limited resources, more studies are needed to assess cost-effectiveness of universal testing prior to nationwide implementation.

In our previous study, we showed that a research-based self-administered family history questionnaire can be considered for use in specialist clinics to facilitate and improve family history documentation [8]. Indeed, a review has reported that a systematic family history tool may add 
significant family health information to current primary care practice [53], and a computer-based decision support system can further facilitate appropriate referral of high risk individuals for genetic services [54,55]. An automatic prompt for IHC or MSI testing may also be incorporated into such a system once routine universal testing is formally established in Australia to improve diagnosis and referral of patients for genetic services. Development of patient information brochure should further assist clinicians when consulting patients as well as to aid patients in making informed decisions about genetic testing.

There are several limitations to this study. Firstly, the response rate was low. This may be in part due to unwillingness to complete a web-based survey or lack of interest in hereditary cancer syndromes. A larger sample size and greater response rate would certainly provide a more accurate view on clinicians' attitudes to genetics referral, however, the response rate in our study is comparable to other web-based studies conducted [56-59]. Selection bias may have occurred because participants had greater interest in hereditary cancer syndromes, more genomic knowledge, or stronger beliefs about their role in providing genetic services. Should this be true, our results would indicate even more strongly a need for improved education and support for clinicians to triage patients with suspected Lynch syndrome. Another limitation faced by our web-based data collection includes the inability to assess the representativeness of Australian healthcare providers due to lack of a national email registry, which may potentially bias our original sampling frame. We also did not know how many men and women within each practice category were asked for the survey initially, as the email broadcast was blinded by the Association for confidential reasons. Although clinicians were not evaluated for low or moderate risk Lynch syndrome-related clinical scenarios, the purpose of this study was to explore recognition of a classical family history suggestive of Lynch syndrome. Despite the abovementioned caveats, findings from this Australian study offer insight into clinicians' knowledge of Lynch syndrome, and their attitudes toward genetic services and referral practices.

\section{Conclusions}

Our study suggested that genetics education is necessary for clinicians in order to improve genetic referral. Further studies should be conducted to examine educational topics selected by clinicians (e.g., genetic risk assessments, basic genomic concepts), and more behavioural research is needed to investigate barriers to patient uptake of referral as well as patients' information needs. An online family history tool with built-in decision support for genetics referral would be helpful in triaging high-risk individuals in general practice. Future research should also focus on feasibility and impact assessment of reflex IHC or MSI and MLH1 methylation testing to identify Lynch syndrome patients as a way to prevent second cancers, and identify carrier relatives for predictive testing.

\section{Acknowledgments}

We would like to thank all the clinicians who participated in the study. We gratefully acknowledge the following experts who contributed their time for the study: Peter Baker, Gillian Mitchell, Judy Kirk, Rachel Susman, Monika Janda, Melanie Price, Ingrid Winship, Michael Gattas, Mary-Anne Young, Barbara Leggett, Phyllis Butow, Jeffrey Goh, Graeme Suthers and Kristine Barlow-Stewart. 


\section{Author Contributions}

Yen Y. Tan was responsible for conception and design; collection, assembly and analysis of data. All authors were responsible for data interpretation, manuscript writing, and final approval of manuscript. Andreas Obermair also provided financial support for the study.

\section{Conflicts of Interest}

The authors declare no conflict of interest.

\section{References}

1. Lynch, H.T.; Watson, P.; Shaw, T.G.; Lynch, J.F.; Harty, A.E.; Franklin, B.A.; Kapler, C.R.; Tinley, S.T.; Liu, B.; Lerman, C. Clinical impact of molecular genetic diagnosis, genetic counseling, and management of hereditary cancer. Cancer 1999, 86, 2449-2456.

2. Dinh, T.A.; Rosner, B.I.; Atwood, J.C.; Boland, C.R.; Syngal, S.; Vasen, H.F.; Gruber, S.B.; Burt, R.W. Health benefits and cost-effectiveness of primary genetic screening for Lynch syndrome in the general population. Cancer Prev. Res. 2011, 4, 9-22.

3. Vasen, H.F.; Blanco, I.; Aktan-Collan, K.; Gopie, J.P.; Alonso, A.; Aretz, S.; Bernstein, I.; Bertario, L.; Burn, J.; Capella, G. Revised guidelines for the clinical management of Lynch syndrome (HNPCC): Recommendations by a group of European experts. Gut 2013, 62, 812-823.

4. Barrow, E.; Hill, J.; Evans, D.G. Cancer risk in Lynch Syndrome. Fam. Cancer 2013, 12, 229-240.

5. Win, A.K.; Lindor, N.M.; Winship, I.; Tucker, K.M.; Buchanan, D.D.; Young, J.P.; Rosty, C.; Leggett, B.; Giles, G.G.; Goldblatt, J. Risks of colorectal and other cancers after endometrial cancer for women with Lynch syndrome. J. Natl. Cancer Inst. 2013, 105, 274-279.

6. Wong, C.; Gibbs, P.; Johns, J.; Jones, I.; Faragher, I.; Lynch, E.; Macrae, F.; Lipton, L. Value of database linkage: Are patients at risk of familial colorectal cancer being referred for genetic counselling and testing? Intern. Med. J. 2008, 38, 328-333.

7. Singh, H.; Schiesser, R.; Anand, G.; Richardson, P.A.; El-Serag, H.B. Underdiagnosis of Lynch syndrome involves more than family history criteria. Clin. Gastroenterol. Hepatol. 2010, 8, 523-529.

8. Tan, Y.Y.; McGaughran, J.; Ferguson, K.; Walsh, M.D.; Buchanan, D.D.; Young, J.P.; Webb, P.M.; Obermair, A.; Spurdle, A.B. Improving identification of lynch syndrome patients: A comparison of research data with clinical records. Int. J. Cancer 2013, 132, 2876-2883.

9. Pujol, P.; Lyonnet, D.S.; Frebourg, T.; Blin, J.; Picot, M.C.; Lasset, C.; Dugast, C.; Berthet, P.; de Paillerets, B.B.; Sobol, H.; et al. Lack of referral for genetic counseling and testing in BRCA1/2 and Lynch syndromes: A nationwide study based on 240,134 consultations and 134,652 genetic tests. Breast Cancer Res. Treat. 2013, 141, 135-144.

10. Grover, S.; Stoffel, E.M.; Bussone, L.; Tschoegl, E.; Syngal, S. Physician assessment of family cancer history and referral for genetic evaluation in colorectal cancer patients. Clin. Gastroenterol. Hepatol. 2004, 2, 813-819.

11. Suther, S.; Goodson, P. Barriers to the provision of genetic services by primary care physicians: A systematic review of the literature. Genet. Med. 2003, 5, 70-76. 
12. Tan, Y.Y.; Noon, L.L.; McGaughran, J.M.; Spurdle, A.B.; Obermair, A. Referral of patients with suspected hereditary breast-ovarian cancer or Lynch syndrome for genetic services: A systematic review. J. Community Med. Health Educ. 2013, doi:10.4172/2161-0711.1000255.

13. Prochniak, C.F.; Martin, L.J.; Miller, E.M.; Knapke, S.C. Barriers to and motivations for physician referral of patients to cancer genetics clinics. J. Genet. Couns. 2011, 21, 305-325.

14. Domanska, K.; Carlsson, C.; Bendahl, P.O.; Nilbert, M. Knowledge about hereditary nonpolyposis colorectal cancer; mutation carriers and physicians at equal levels. BMC Med. Genet. 2009, doi:10.1186/1471-2350-10-30.

15. Frey, M.K.; Biewald, M.A.; Worley, M.J., Jr.; Taylor, J.S.; Lin, S.N.; Holcomb, K. Lynch Syndrome: Awareness among Medical Students at a United States Medical School. Curr. Womens Health Rev. 2012, 8, 242-247.

16. Tan, Y.Y.; Fitzgerald, L.J. Barriers and Motivators for Referral of Patients with Suspected Lynch Syndrome to Cancer Genetic Services: A Qualitative Study. J. Pers. Med. 2014, 4, 20-34.

17. Vasen, H.; Watson, P.; Mecklin, J.; Lynch, H. New clinical criteria for hereditary nonpolyposis colorectal cancer (HNPCC, Lynch syndrome) proposed by the International Collaborative group on HNPCC. Gastroenterology 1999, 116, 1453-1456.

18. Umar, A.; Boland, C.R.; Terdiman, J.P.; Syngal, S.; Chapelle, A.; Rüschoff, J.; Fishel, R.; Lindor, N.M.; Burgart, L.J.; Hamelin, R.; et al. Revised Bethesda Guidelines for hereditary nonpolyposis colorectal cancer (Lynch syndrome) and microsatellite instability. J. Natl. Cancer Inst. 2004, 96, 261-268.

19. Lancaster, J.M.; Powell, C.B.; Kauff, N.D.; Cass, I.; Chen, L.M.; Lu, K.H.; Mutch, D.G.; Berchuck, A.; Karlan, B.Y.; Herzog, T.J.; et al. Society of Gynecologic Oncologists Education Committee statement on risk assessment for inherited gynecologic cancer predispositions. Gynecol. Oncol. 2007, 107, 159-162.

20. Gaff, C.L.; Aitken, M.; Flouris, A.; Metcalfe, S.A. A model for the development of genetics education programs for health professionals. Genet. Med. 2007, 9, 451-457.

21. Buchanan, D.D.; Tan, Y.Y.; Walsh, M.D.; Clendenning, M.; Metcalf, A.M.; Ferguson, K.; Arnold, S.T.; Thompson, B.A.; Lose, F.A.; Parsons, M.T.; et al. Tumor mismatch repair immunohistochemistry and DNA MLH1 methylation testing of patients with endometrial cancer diagnosed at age younger than 60 years optimizes triage for population-level germline mismatch repair gene mutation testing. J. Clin. Oncol. 2014, 32, 90-100.

22. CAP. Technology Assessment Committee. POET Report: Perspectives on Emerging Technology Prognostic Uses of MSI Testing 2011. Available online: http:/www.cap.org/apps/docs/committees/ technology/microsatellite_testing.pdf (accessed on 4 April 2014).

23. Schmeler, K.M.; Lynch, H.T.; Chen, L.M.; Munsell, M.F.; Soliman, P.T.; Clark, M.B.; Daniels, M.S.; White, K.G.; Boyd-Rogers, S.G.; Conrad, P.G.; et al. Prophylactic surgery to reduce the risk of gynecologic cancers in the Lynch syndrome. N. Engl. J. Med. 2006, 354, 261-269.

24. Lu, K.H.; Loose, D.S.; Yates, M.S.; Nogueras-Gonzalez, G.M.; Munsell, M.F.; Chen, L.M.; Lynch, H.; Cornelison, T.; Boyd-Rogers, S.; Rubin, M.; et al. Prospective, multi-center randomized intermediate biomarker study of oral contraceptive $v s$. depo-provera for prevention of endometrial cancer in women with Lynch Syndrome. Cancer Prev. Res. 2013, 6, 774-781. 
25. Jarvinen, H.J.; Aarnio, M.; Mustonen, H.; Aktan-Collan, K.; Aaltonen, L.A.; Peltomaki, P.; de la Chapelle, A.; Mecklin, J.P. Controlled 15-year trial on screening for colorectal cancer in families with hereditary nonpolyposis colorectal cancer. Gastroenterology 2000, 118, 829-834.

26. Jarvinen, H.J.; Renkonen-Sinisalo, L.; Aktan-Collan, K.; Peltomaki, P.; Aaltonen, L.A.; Mecklin, J.P. Ten years after mutation testing for Lynch syndrome: Cancer incidence and outcome in mutation-positive and mutation-negative family members. J. Clin. Oncol. 2009, 27, 4793-4797.

27. De Jong, A.E.; Hendriks, Y.M.; Kleibeuker, J.H.; de Boer, S.Y.; Cats, A.; Griffioen, G.; Nagengast, F.M.; Nelis, F.G.; Rookus, M.A.; Vasen, H.F. Decrease in mortality in Lynch syndrome families because of surveillance. Gastroenterology 2006, 130, 665-671.

28. Batra, S.; Valdimarsdottir, H.; McGovern, M.; Itzkowitz, S.; Brown, K. Awareness of genetic testing for colorectal cancer predisposition among specialists in gastroenterology. Am. J. Gastroenterol. 2002, 97, 729-733.

29. Kelly, K.M.; Love, M.M.; Pearce, K.A.; Porter, K.; Barron, M.A.; Andrykowski, M. Cancer risk assessment by rural and Appalachian family medicine physicians. J. Rural Health 2009, 25, 372-377.

30. Carroll, J.C.; Cappelli, M.; Miller, F.; Wilson, B.J.; Grunfeld, E.; Peeters, C.; Hunter, A.G.; Gilpin, C.; Prakash, P. Genetic services for hereditary breast/ovarian and colorectal cancers-Physicians' awareness, use and satisfaction. Community Genet. 2008, 11, 43-51.

31. Freedman, A.N.; Wideroff, L.; Olson, L.; Davis, W.; Klabunde, C.; Srinath, K.P.; Reeve, B.B.; Croyle, R.T.; Ballard-Barbash, R. US physicians' attitudes toward genetic testing for cancer susceptibility. Am. J. Med. Genet. A 2003, 120, 63-71.

32. Cox, S.L.; Zlot, A.I.; Silvey, K.; Elliott, D.; Horn, T.; Johnson, A.; Leman, R.F. Patterns of cancer genetic testing: A randomized survey of Oregon clinicians. J. Cancer Epidemiol. 2012, doi:10.1155/2012/294730.

33. Linstone, H.; Turoff, M. The Delphi Method: Techniques and Applications; Addison-Wesley Pub. Co.: Newark, NJ, USA, 1975.

34. Cancer Australia. Report to the Nation-Uterine Cancer 2012. Available online: http://canceraustralia.gov.au/publications-resources/cancer-australia-publications/report-nationuterine-cancer-2012 ( accessed on 4 April 2014).

35. Cancer Australia. Diagnostic guide for general practitioners and gynaecologists. Available online: http://www.canceraustralia.gov.au/sites/default/files/publications/ncgc-vaginal-bleeding-flowchartsmarch-20111_504af02038614.pdf(accessed on 17 April 2014).

36. Wakefield, C.; Kasparian, N.; Meiser, B.; Homewood, J.; Kirk, J.; Tucker, K. Attitudes toward genetic testing for cancer risk after genetic counseling and decision support: A qualitative comparison between hereditary cancer types. Genet. Test. 2007, 11, 401-412.

37. Australian Law Reform Commission. Essentially yours: The protection of human genetic information in Australia (ALRC Report 96). Genetic counselling and medical education: Access to medical genetic testing and counselling. Available online: http://www.alrc.gov.au/publications/23-geneticcounselling-and-medical-education/access-medical-genetic-testing-and-counsel/ (accessed on 8 October 2013).

38. McCann, S.; MacAuley, D.; Barnett, Y. Genetic consultations in primary care: GPs' responses to three scenarios. Scand. J. Prim. Health Care 2005, 23, 109-114. 
39. Sifri, R.; Myers, R.; Hyslop, T.; Turner, B.; Cocroft, J.; Rothermel, T.; Grana, J.; Schlackman, N. Use of cancer susceptibility testing among primary care physicians. Clin. Genet. 2003, 64, 355-360.

40. Fry, A.; Campbell, H.; Gudmundsdottir, H.; Rush, R.; Porteous, M.; Gorman, D.; Cull, A. GPs' views on their role in cancer genetics services and current practice. Fam. Pract. 1999, 16, 468-474.

41. Renaud, M.C.; Le, T.; Le, T.; Bentley, J.; Farrell, S.; Fortier, M.P.; Giede, C.; Kupets, R.; Plante, M.; Power, P.; et al. Epidemiology and investigations for suspected endometrial cancer. J. Obstet. Gynaecol. Can. 2013, 35, 380-383.

42. Palomaki, G.E.; McClain, M.R.; Melillo, S.; Hampel, H.L.; Thibodeau, S.N. EGAPP supplementary evidence review: DNA testing strategies aimed at reducing morbidity and mortality from Lynch syndrome. Genet. Med. 2009, 11, 42-65.

43. Acheson, L.S.; Stange, K.C.; Zyzanski, S. Clinical genetics issues encountered by family physicians. Genet. Med. 2005, 7, 501-508.

44. Taylor, M.R.; Edwards, J.G.; Ku, L. Lost in transition: Challenges in the expanding field of adult genetics. Am. J. Med. Genet. C Semin Med. Genet. 2006, 142C, 294-303.

45. Qureshi, N.; Wilson, B.; Santaguida, P.; Carroll, J.; Allanson, J.; Culebro, C.R.; Brouwers, M.; Raina, P. Collection and use of cancer family history in primary care. Evid. Rep. Technol. Assess. 2007, 159, 1-84.

46. Watson, E.K.; Shickle, D.; Qureshi, N.; Emery, J.; Austoker, J. The "new genetics" and primary care: GPs' views on their role and their educational needs. Fam. Pract. 1999, 16, 420-425.

47. Lanceley, A.; Eagle, Z.; Ogden, G.; Gessler, S.; Razvi, K.; Ledermann, J.A.; Side, L. Family history and women with ovarian cancer: Is it asked and does it matter?: An observational study. Int. J. Gynecol. Cancer 2012, 22, 254-259.

48. Trano, G.; Wasmuth, H.H.; Sjursen, W.; Hofsli, E.; Vatten, L.J. Awareness of heredity in colorectal cancer patients is insufficient among clinicians: A Norwegian population-based study. Colorectal Dis. 2009, 11, 456-461.

49. Van Altena, A.M.; van Aarle, S.; Kiemeney, L.A.; Hoogerbrugge, N.; Massuger, L.F.; de Hullu, J.A. Adequacy of family history taking in ovarian cancer patients: A population-based study. Fam. Cancer 2012, 11, 343-349.

50. Suthers, G.K.; Armstrong, J.; McCormack, J.; Trott, D. Letting the family know: Balancing ethics and effectiveness when notifying relatives about genetic testing for a familial disorder. J. Med. Genet. 2006, 43, 665-670.

51. Keogh, L.A.; Southey, M.C.; Maskiell, J.; Young, M.A.; Gaff, C.L.; Kirk, J.; Tucker, K.M.; Rosenthal, D.; McCredie, M.R.; Giles, G.G. Uptake of offer to receive genetic information about BRCA1 and BRCA2 mutations in an Australian population-based study. Cancer Epidemiol. Biomark. Prev. 2004, 13, 2258-2263.

52. Wakefield, C.E.; Ratnayake, P.; Meiser, B.; Suthers, G.; Price, M.A.; Duffy, J.; Tucker, K.; Kathleen Cuningham National Consortium for Research into Familial Breast Cancer (kConFab). "For all my family's sake, I should go and find out": An Australian report on genetic counseling and testing uptake in individuals at high risk of breast and/or ovarian cancer. Genet. Test. Mol. Biomark. 2011, 15, 379-385. 
53. Qureshi, N.; Carroll, J.C.; Wilson, B.; Santaguida, P.; Allanson, J.; Brouwers, M.; Raina, P. The current state of cancer family history collection tools in primary care: A systematic review. Genet. Med. 2009, 11, 495-506.

54. Emery, J.; Morris, H.; Goodchild, R.; Fanshawe, T.; Prevost, A.T.; Bobrow, M.; Kinmonth, A.L. The GRAIDS Trial: A cluster randomised controlled trial of computer decision support for the management of familial cancer risk in primary care. Br. J. Cancer 2007, 97, 486-493.

55. Scheuner, M.T.; Hamilton, A.B.; Peredo, J.; Sale, T.J.; Austin, C.; Gilman, S.C.; Bowen, M.S.; Goldzueig, C.L.; Lee, M.; Mittman, B.S.; et al. A cancer genetics toolkit improves access to genetic services through documentation and use of the family history by primary-care clinicians.

Genet. Med. 2014, 16, 60-69.

56. Braithwaite, D.; Emery, J.; de Lusignan, S.; Sutton, S. Using the Internet to conduct surveys of health professionals: A valid alternative? Fam. Pract. 2003, 20, 545-551.

57. Scott, A.; Jeon, S.H.; Joyce, C.M.; Humphreys, J.S.; Kalb, G.; Witt, J.; Leahy, A. A randomised trial and economic evaluation of the effect of response mode on response rate, response bias, and item non-response in a survey of doctors. BMC Med. Res. Methodol. 2011, doi:10.1186/14712288-11-126.

58. Chen, L.-S.; Kwok, O.-M.; Goodson, P. US health educators' likelihood of adopting genomic competencies into health promotion. Am. J. Public Health 2008, 98, 1651-1657.

59. McMahon, S.R.; Iwamoto, M.; Massoudi, M.S.; Yusuf, H.R.; Stevenson, J.M.; David, F.; Chu, S.Y.; Pickering, L.K. Comparison of e-mail, fax, and postal surveys of pediatricians. Pediatrics 2003, 111, e299-e303.

\section{Appendix 1: Questionnaire}

Health Professionals' Knowledge and Attitudes towards Genetic Services for Patients with or at High-Risk of Lynch syndrome

This survey is about health professionals' knowledge and attitudes towards genetic services. Genetic services refer to the delivery of genetic counselling and risk assessment, and testing for patients and families with or at high-risk of hereditary syndrome.

\section{Demographic of Respondents}

1. What is your gender?

O Male

O Female

2. What is your age?
O $18-29$
O $30-39$
O 40-49
O 50-59
○ $60+$ 
3. What is your current specialty?

$\bigcirc$ General practice

Gynaecology

Gastroenterology

Gynaecology oncology

O Medical oncology

O Radiation oncology

General surgery

O Colorectal surgery

Other (please specify

4. How long have you been practicing in your current field?
O $0-5$ years
O 6-10 years
O 11-20 years
More than 20 years

5. What is the postcode of your primary location of practice?

Please specify

\section{You and Your Practice}

The following section is about you and your referral practice. This is not a test. Your replies are anonymous and will be treated confidentially. Please answer all items.

6. In the past 12 months, have you referred patients for:

\begin{tabular}{llccc}
\hline & Yes & No & Not sure \\
\hline a. Genetic services? & $\square^{1}$ & $\square^{2}$ & \\
b. DNA mutation testing? & $\square^{1}$ & $\square^{2}$ & $\square^{3}$ \\
c. Tumour immunohistochemistry (IHC) testing & $\square^{1}$ & $\square^{2}$ & $\square^{3}$ \\
d. Tumour microsatellite instability (MSI) testing & $\square^{1}$ & $\square^{2}$ & $\square^{3}$ \\
\hline
\end{tabular}

7. Do you consider the following testing a germline test?

\begin{tabular}{cccc}
\hline & Yes & No & Not sure \\
\hline a. IHC testing? & $\square^{1}$ & $\square^{2}$ & $\square^{3}$ \\
b. MSI testing? & $\square^{1}$ & $\square^{2}$ & $\square^{3}$ \\
\hline
\end{tabular}




\section{Case Scenario}

Please read the following patient background before answering Questions 8 and 9. This is not a test. Your replies are anonymous and will be treated confidentially. Please answer all items. If you are unfamiliar with a pedigree format and need more explanation, please read the paragraph next to the pedigree below.

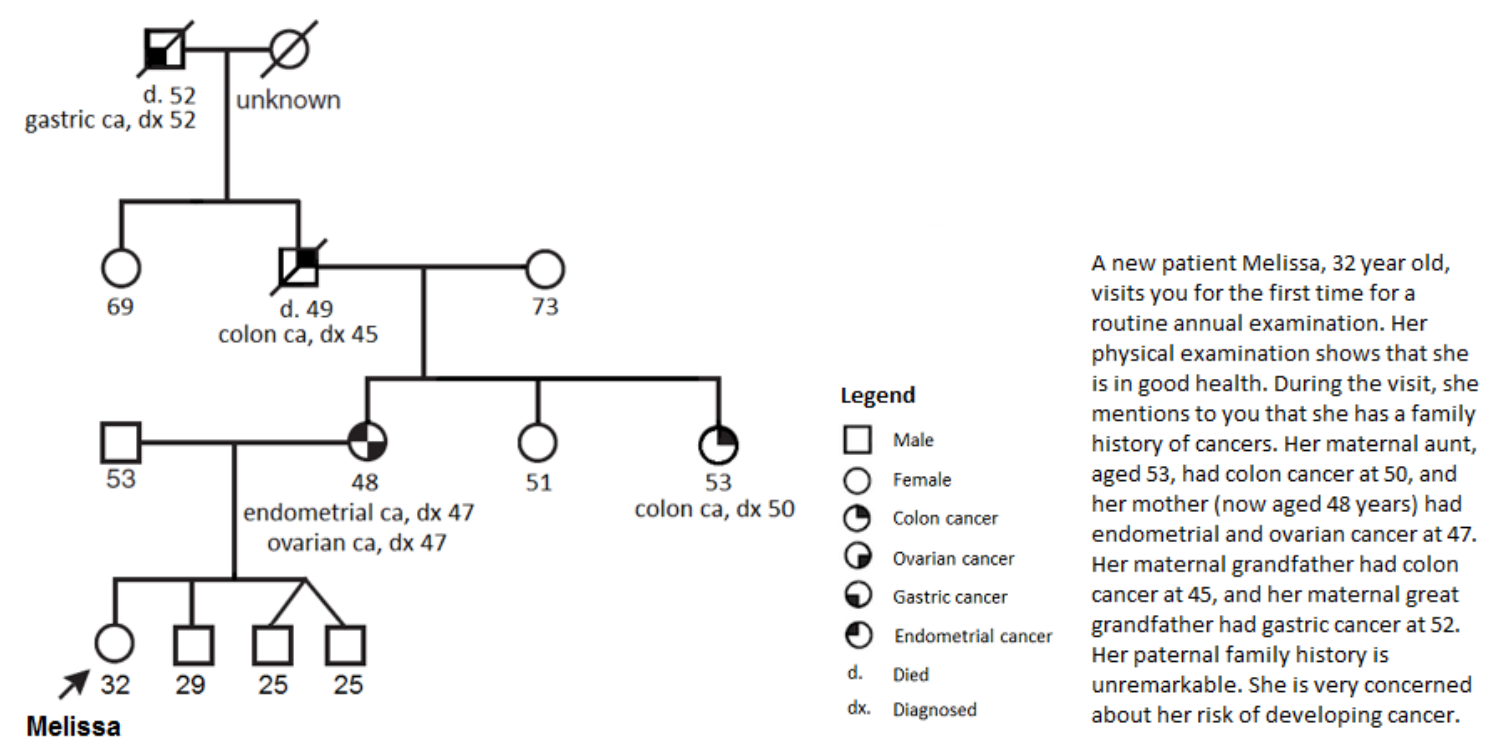

8. In your medical opinion, what is Melissa's risk for developing the following cancers as compared to the general population? (Please answer all items).

\begin{tabular}{lccccc}
\hline & Much higher & Somewhat higher & Same & Somewhat lower & Not sure \\
\hline a. Breast cancer & $\square^{5}$ & $\square^{4}$ & $\square^{3}$ & $\square^{2}$ & $\square^{1}$ \\
b. Gastric cancer & $\square^{5}$ & $\square^{4}$ & $\square^{3}$ & $\square^{2}$ & $\square^{1}$ \\
c. Ovarian cancer & $\square^{5}$ & $\square^{4}$ & $\square^{3}$ & $\square^{2}$ & $\square^{1}$ \\
d. Thyroid cancer & $\square^{5}$ & $\square^{4}$ & $\square^{3}$ & $\square^{2}$ & $\square^{1}$ \\
e. Colorectal cancer & $\square^{5}$ & $\square^{4}$ & $\square^{3}$ & $\square^{2}$ & $\square^{1}$ \\
f. Endometrial cancer & $\square^{5}$ & $\square^{4}$ & $\square^{3}$ & $\square^{2}$ & $\square^{1}$ \\
\hline
\end{tabular}

9. About a year later, Melissa was diagnosed with endometrial cancer. How would you proceed?

\begin{tabular}{|c|c|c|c|c|c|}
\hline & Very likely & Somewhat likely & Not likely & Very unlikely & Not sure \\
\hline a. Offer surveillance & $\square^{5}$ & $\square^{4}$ & $\square^{3}$ & $\square^{2}$ & $\square^{1}$ \\
\hline b. Referral to a geneticist & $\square^{5}$ & $\square^{4}$ & $\square^{3}$ & $a^{2}$ & $\square^{1}$ \\
\hline c. Family history assessment & $\square^{5}$ & $\square^{4}$ & $\square^{3}$ & $\square^{2}$ & $\square^{1}$ \\
\hline d. Discussion of risk-reducing surgery & $\square^{5}$ & $\square^{4}$ & $\square^{3}$ & $\square^{2}$ & $\square^{1}$ \\
\hline e. Referral to a non-genetics specialist & $\square^{5}$ & $\square^{4}$ & $\square^{3}$ & $\square^{2}$ & $\square^{1}$ \\
\hline $\begin{array}{l}\text { f. Order genetic testing for } \\
\text { germline mutations }\end{array}$ & $\square^{5}$ & $\square^{4}$ & $\square^{3}$ & $a^{2}$ & $\square^{1}$ \\
\hline $\begin{array}{l}\text { g. Order pre-genetic testing of tumour } \\
\text { tissue (e.g., MSI or IHC) }\end{array}$ & $\square^{5}$ & $\square^{4}$ & $\square^{3}$ & $a^{2}$ & $\square^{1}$ \\
\hline $\begin{array}{l}\text { h. Discussion about Lynch syndrome } \\
\text { cancers with patient }\end{array}$ & $\square^{5}$ & $\square^{4}$ & $\square^{3}$ & $a^{2}$ & $\square^{1}$ \\
\hline i. No action & $\square^{5}$ & $\square^{4}$ & $\square^{3}$ & $\square^{2}$ & $\square^{1}$ \\
\hline
\end{tabular}


10. If you have chosen to offer surveillance, what would you offer? (check all that apply)

\section{$\square$ Colonoscopy}

Gastroscopy

口 CA125

$\square$ Mammography

$\square$ Other, please specify

11. If you have chosen to discuss risk-reducing surgery with patients, what kind of risk-reducing surgery would you discuss with the patient?

Please specify

\section{General Attitudes about Genetic Services}

The flowing section is about why you would or would not refer patients for genetic services. We would like you to answer the questions whether or not you currently use genetic services.

12. In your opinion, which of the following factors play a role in your decision to refer a patient for genetic services? (Check all that apply)

$\square^{1}$ Patient interest or request

$\square^{2}$ Ethical and legal responsibility

$\square^{3}$ Reassurance for the patient and family

$\square^{4}$ To provide genetic counselling for the patient

$\square^{5}$ Genetic testing for germline mutations

$\square^{6}$ To provide appropriate cancer risk assessment for the patient

$\square^{7}$ To provide appropriate screening and management for the patient

$\square^{8}$ To provide appropriate screening and/or management for the patients' family

$\square^{9}$ Other, please specify:

13. In your opinion, which of the following factors play a role in your decision to NOT refer a patient for genetic services? (Check all that apply)

$\square^{1}$ I do not feel it is my responsibility

$\square^{2}$ I do not have access to a genetic health service

$\square^{3}$ Patients may be at risk for insurance discrimination

$\square^{4}$ Long waiting time for appointment at a genetic clinic

$\square^{5}$ Patient was not interested when referral was offered

$\square^{6}$ I do not feel familiar with hereditary cancer syndromes

$\square^{7}$ Patient is unlikely to benefit from genetic counselling and/or testing

$\square^{8}$ I do not know how to make a referral to the local genetic health service

$\square^{9}$ Recommendations and guidelines are not available to select patients for referral

$\square^{10}$ Other, please specify: 
14. Who do you think is best to refer patients for genetic services (i.e., to make the initial offer)? (Please choose only one of the following, and provide the reason(s) for your selection)

O General practitioners

O Gynaecologists

Gastroenterologists

Gynaecology oncologists

Medical oncologists

O Radiation oncologists

C Colorectal surgeons

O General surgeons

Ony of the above

Make a comment on your choice here:

15. When is the best time for the initial referral for genetic services to be made to the patient? (Please choose only one of the following, and provide the reason(s) for your selection)

When family history is collected

$\bigcirc$ At diagnosis of cancer

After surgery and before commencement of adjuvant therapy

$O$ During adjuvant therapy

After treatment is finished

At any time

Make a comment on your choice here:

16. I feel my role as a physician includes: (Check all that apply)

$\square^{1}$ Providing emotional support after genetic testing

$\square^{2}$ Identifying patients for referral to genetic services

$\square^{3}$ Interpreting germline DNA-based genetic test results

$\square^{4}$ Collecting a three-generation family history information

$\square^{5}$ Ordering pre-genetic testing of tumour tissue (e.g. MSI or IHC)

$\square^{6}$ Counselling patients about their cancer risks after genetic testing

$\square^{7}$ Counselling patients about their cancer risks before genetic testing

$\square^{8}$ Calculating relative risk of cancer associated with family cancer history

$\square^{9}$ Discussing the need for cancer surveillance or prophylaxis with patients when required

$\square^{10}$ Providing regular clinical examination and care to patients with hereditary cancer syndromes

$\square^{11}$ Other, please specify: 
17. In your opinion, which of the following would support your practice? (Please choose the appropriate response for each item)

\begin{tabular}{|c|c|c|c|c|c|}
\hline & $\begin{array}{l}\text { Very } \\
\text { likely }\end{array}$ & $\begin{array}{l}\text { Somewhat } \\
\text { likely }\end{array}$ & Not likely & $\begin{array}{c}\text { Very } \\
\text { unlikely }\end{array}$ & Not sure \\
\hline a. Clear referral guideline & $\square^{5}$ & $\square^{4}$ & $\square^{3}$ & $a^{2}$ & $\square^{1}$ \\
\hline b. Online risk assessment tool & $\square^{5}$ & $\square^{4}$ & $\square^{3}$ & $\square^{2}$ & $a^{1}$ \\
\hline c. Continuing genetic education programmes & $\square^{5}$ & $\square^{4}$ & $\square^{3}$ & $\square^{2}$ & $a^{1}$ \\
\hline d. Genetic information brochure for patients & $\square^{5}$ & $\square^{4}$ & $\square^{3}$ & $\square^{2}$ & $\square^{1}$ \\
\hline $\begin{array}{l}\text { e. A coordinator in clinic to collect patient } \\
\text { family history }\end{array}$ & $\square^{5}$ & $\square^{4}$ & $\square^{3}$ & $\square^{2}$ & $\square^{1}$ \\
\hline $\begin{array}{l}\text { f. A genetic counsellor in clinic to assess risk } \\
\text { and to facilitate referral }\end{array}$ & $\square^{5}$ & $\square^{4}$ & $\square^{3}$ & $\square^{2}$ & $\square^{1}$ \\
\hline $\begin{array}{l}\text { g. A computerized family history tool with } \\
\text { decision support for referral }\end{array}$ & $\square^{5}$ & $\square^{4}$ & $\square^{3}$ & $\square^{2}$ & $\square^{1}$ \\
\hline $\begin{array}{l}\mathrm{h} \text {. The presence of a genetic counsellor in a } \\
\text { multidisciplinary tumour board meeting }\end{array}$ & $\square^{5}$ & $\square^{4}$ & $\square^{3}$ & $\square^{2}$ & $\square^{1}$ \\
\hline
\end{tabular}

18. Is there anything else you would like to tell us about?

19. If you would like to receive a copy of the research summary report, please enter your email address here: 
Appendix 2. Risk Management for Lynch Syndrome (eviQ version 2) Risk Management for Lynch Syndrome

\author{
ID: $001410(V 2)$
}

Approved: 18 Oct 2009

Last Modified: 29 Jan 2014

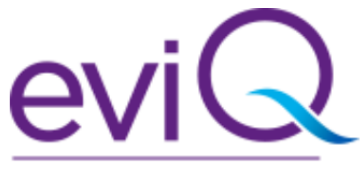

Cancer Treatments Online

Review Due:29 Aug 2014

Information for families with Lynch Syndrome

Contacting family members about hereditary cancer

Lynch Syndrome is an autosomal dominant condition caused by germline mutations in the mismatch repair genes MLH1, MSH2, MSH6 or PMS2.

\title{
Target group
}

known mismatch repair (MMR) gene mutation carrier

$50 \%$ risk of being a MMR gene mutation carrier

Exclusion criteria

Not suitable for:

individuals from families fulfilling Amsterdam I or IIclinical criteria with active exclusion of MMR defectby tumour testing or in whom no molecular tumour testing or germline testing is possible

familial gastric cancer syndrome

$n$ individuals and first degree relatives of individuals with a tumour showing loss of functional MMR pathway but in whom

no germline MMR mutation has been identified

\section{Lifetime risk of cancer}

\begin{tabular}{|c|c|c|}
\hline Cancer & $\begin{array}{l}\text { Lynch syndrome } \\
\text { to age } 70 \text { yrs } *, * *, 1\end{array}$ & General population to age 85 yrs \\
\hline Colorectal (male) & $38 \%$ & $10 \% * * *$ \\
\hline Colorectal (female) & $31 \%$ & $6.6 \% * * *$ \\
\hline Endometrial & $33 \%$ & $?-3 \%$ \\
\hline Gastric & $7 \%$ & $? \%$ \\
\hline Ovarian & $9 \%$ & $?-2 \%$ \\
\hline Urothelial & $\leq 3 \%$ & $? \%$ \\
\hline Brain & $\leq 3 \%$ & $? .6 \%$ \\
\hline Small Bowel & $\leq 3 \%$ & $0.01 \%$ \\
\hline \multicolumn{3}{|c|}{ * Higher figures obtained in papers not corrected for ascertainment bias } \\
\hline \multicolumn{3}{|c|}{ ** Combined data for MLH1, MSH2, MSH6, but risks shown do vary per gene } \\
\hline \multicolumn{3}{|c|}{$\begin{array}{l}\text { *** This data does not take into account the impact of surveillance. } \\
\text { Data Source: NSW Central Cancer Registry } 2008 \text { final dataset and NSW Health Outcomes Information Statistical Toolkit } \\
\text { (HOIST). }\end{array}$} \\
\hline
\end{tabular}

\section{Cancer risk management guidelines}

All patients should be entered on a local hereditary cancer registry for information and surveillance reminders. (Link to Hereditary Cancer Registry) 
Risk Management for Lynch Syndrome

\begin{tabular}{|c|c|c|c|}
\hline \multirow{3}{*}{ Colorectal } & Surgical & $\mathrm{n}$ & consider subtotal colectomy in selected individuals \\
\hline & Surveillance & n & $\begin{array}{l}\text { annual colonoscopy from age } 25 \text { yrs or } 5 \text { yrs younger than youngest } \\
\text { affected if <30yrs } \\
\text { review frequency of colonoscopy at age } 60 \text { yrs with a view to reduced } \\
\text { frequency }\end{array}$ \\
\hline & $\begin{array}{l}\text { Risk- } \\
\text { reducing } \\
\text { medication }\end{array}$ & n & $\begin{array}{l}\text { there may be a reduction of risk in taking aspirin however the } \\
\text { appropriate dose is not yet defined (preliminary data) }\end{array}$ \\
\hline \multirow{2}{*}{ Endometrial } & Surgical & n & recommend hysterectomy after childbearing complete or from age $40 y$ rs \\
\hline & Surveillance & n & $\begin{array}{l}\text { there is no evidence for transvaginal ultrasound (TVU) and/or aspiration } \\
\text { biopsy }\end{array}$ \\
\hline \multirow{2}{*}{ Ovarian } & Surgical & n & $\begin{array}{l}\text { recommend risk reducing salpingo-oophorectomy (RRSO) at time of } \\
\text { hysterectomy }\end{array}$ \\
\hline & Surveillance & $n$ & $\begin{array}{l}\text { there is no evidence for serum CA125 and/or transvaginal ultrasound } \\
\text { (TVU) }\end{array}$ \\
\hline Gastric & Surveillance & $n$ & $\begin{array}{l}\text { consider second yrly gastroscopy from age } 30 \text { yrs in families with gastric } \\
\text { cancer or those at high ethnic risk - e.g. Chinese, Korean, Chilean and } \\
\text { Japanese }\end{array}$ \\
\hline Urothelial & Surveillance & n & $\begin{array}{l}\text { no evidence of benefit but patients encouraged to report symptoms e.g. } \\
\text { haematuria }\end{array}$ \\
\hline
\end{tabular}

Management of associated health problems and side effects

\section{Management of early menopause}

As there is no conclusive data regarding an increased risk of breast cancer in Lynch Syndrome the use of Hormonal Replacement Therapy (HRT) after oophorectomy is not contraindicated.

\section{Evidence for risk management guidelines}

\section{Colorectal cancer}

Surgical

No controlled trials regarding partial versus total colectomy for the management of colorectal cancer (CRC) are available. One decision analysis has reported an increase in life expectancy with subtotal colectomy ${ }^{2}$.

\section{Surveillance}

A study of 114 Lynch Syndrome families comparing outcomes of screening at intervals of $\leq 2 y$ rs with $>2 y r s$ demonstrated CRCs diagnosed at higher stage with longer interval surveillance. Evidence supports screening 1-2yrly ${ }^{3}$.

Since $57 \%$ of the neoplasms in Lynch Syndrome occur proximal to the splenic flexure ${ }^{4}$, visualisation to the caecum is essential. Given the high metachronous CRC risk in Lynch Syndrome $(16 \% 10 \mathrm{yrs} \text { after a partial colectomy })^{3}$, total colectomy should be discussed if a CRC is detected on surveillance.

\section{Endometrial cancer}

\section{Surgical}

Hysterectomy and RRSO are the only proven interventions which significantly reduce the risk of both endometrial and ovarian cancer ${ }^{5}$. 
Surveillance

There is no evidence to support a survival benefit from TVU and aspiration biopsy ${ }^{3}$. Where possible, surveillance should be offered in the context of a clinical trial ${ }^{5}$.

Ovarian cancer

Surgical

Risk reducing salpingo-oophorectomy (RRSO) reduces the risk of developing ovarian cancer in mutation carriers. One study demonstrated no cases of ovarian cancer amongst women who had undergone RRSO compared with $5 \%$ of controls being diagnosed with ovarian cancer with mean follow up of $7 \mathrm{yrs}^{\mathbf{6}}$.

Surveillance

Data extrapolated from other high risk groups demonstrates annual TVU and serum CA125 levels do not detect ovarian cancers at an earlier stage, nor do they affect outcomes ${ }^{5}$. This form of screening is also associated with a high false positive rate requiring surgical intervention ${ }^{7}$.

Gastric cancer

Surveillance

There is no evidence supporting the role of gastroscopy in the surveillance for gastric cancer in Lynch syndrome patients ${ }^{\mathbf{8}}$, however, InSiGHT has recommended gastroscopy in families at high risk of gastric cancer ${ }^{\mathbf{9}}$.

Urothelial transitional cell carcinoma

Surveillance

There is no evidence for the role of urine cytology in the surveillance of urothelial carcinomas in MMR gene carriers. One study of individuals with confirmed or suspected Lynch Syndrome demonstrated urine cytology had a sensitivity for malignancy of only $29 \%$

\section{Support and information}

First degree relatives, (parents, brothers/sisters and children) are at 50\% risk of having inherited the condition. First degree relatives should be referred to a local Family Cancer Clinic.

Link to an information sheet on contacting relatives

Website resources

Centre for Genetics Education NSW Health

Association of Genetic Support of Australasia INC (AGSA)

Link to Hereditary Cancer Registry

\section{References}

1. Bonadona, V., B. Bonaiti, S. Olschwang, et al. 2011. "Cancer risks associated with germline mutations in MLH1, MSH2, and MSH6 genes in Lynch syndrome." JAMA 305(22):2304-2310

2. de Vos tot Nederveen Cappel, W. H., E. Buskens, P. van Duijvendijk, et al. 2003. "Decision analysis in the surgical treatment of colorectal cancer due to a mismatch repair gene defect." Gut 52(12):1752-1755.

3. de Vos tot Nederveen Cappel, Wouter ,H. 2002. "Surveillance for hereditary nonpolyposis colorectal cancer: a long-term study on 114 families." Dis Colon Rectum. 45(12):1588-1594.

4. Mecklin JP., Aarnia M., Laara E et al 2006 "Development of Colorectal Tumors in Colonoscopic Surveillance in Lynch Syndrome" Gastroenterology Vol 133(4)1093-1093

5. Renkonen-Sinisalo L, Bützow R, Leminen A, et al. 2007 "Surveillance for endometrial cancer in hereditary nonpolyposis colorectal cancer syndrome." Int J Cancer. Feb 15;120(4):821-4.

6. Schmeler, K. M., H. T. Lynch, L. M. Chen, et al. 2006. "Prophylactic surgery to reduce the risk of gynecologic cancers in the Lynch syndrome." N Engl J Med 354(3):261-269.

7. Woodward, E. R., H. V. Sleightholme, et al. (2007). "Annual surveillance by CA125 and transvaginal ultrasound for ovarian cancer in both high-risk and population risk women is ineffective." Bjog 114(12): 1500-9.

8. Renkonen-Sinisalo L, Sipponen P, Aarnio M, et al 2002 "No support for endoscopic surveillance for gastric cancer in hereditary non-polyposis colorectal cancer." Scand J Gastroenterol. May;37(5):574-7.

9. Weber T, 1996. "Clinical surveillance recommendations adopted for HNPCC. " The Lancet, Volume 348, Page 465.

10. Myrhoj, T., M. B. Andersen and I. Bernstein. 2008. "Screening for urinary tract cancer with urine cytology in Lync syndrome and familial colorectal cancer." Fam Cancer 7(4):303-307. 
Risk Management for Lynch Syndrome

The currency of this information is guaranteed only up until the date of printing, for any updates please check www.eviq.org.au

- 07 May 2014

Page 4 of 4

(C) 2014 by the authors; licensee MDPI, Basel, Switzerland. This article is an open access article distributed under the terms and conditions of the Creative Commons Attribution license (http://creativecommons.org/licenses/by/3.0/). 